\title{
TREATMENT OF VAGINAL TRICHOMONIASIS WITH 2-ACETYLAMINO-5-NITROTHIAZOLE (AMINITROZOLE) GIVEN ORALLY*
}

\author{
BY \\ R. R. WILLCOX \\ St Mary's Hospital, London
}

\section{Introduction}

Trichomoniasis is one of the commonest and most troublesome conditions encountered in gynaecological and venereal disease clinics. Inadequate methods of recognition of $T$. vaginalis have in the past impeded the acquisition of knowledge of its transmission. Inadequate methods of treatment have provided many disappointments for both patient and doctor on account of the high relapse rate with the many preparations which have proved so lethal to the parasite in vitro. In recent years, the importance of the sexual transmission of trichomoniasis has been increasingly stressed. The use of cultures for diagnosis has enabled the parasite to be found more easily in the seminal fluid of the consorts of women suffering from this infection. For example, Perl, Guttmacher, and Raggazoni (1956) found $T$. vaginalis by culture in the semen of 28 ( 58 per cent.) out of 48 husbands of wives with vaginal trichomoniasis.

To date, the only treatments which will abolish the parasite from view, at least for a time, have been local. The frequent relapse rate has suggested that the parasite may remain too inaccessible in Skene's tubules, Bartholin's glands, the bladder, or the rectum in the female, or in the prostate, seminal vesicles, or Cowper's or Tyson's glands in the male, to result in re-infection of the vagina. That there is an urgent need for an effective drug which can be given systemically to both sexes has been appreciated for many years by all who have had to treat vaginal trichomoniasis. Hopes that neoarsphenamine, penicillin, Atebrin, and other chemotherapeutic substances would serve were never realized.

Waletsky (1950) found that the drug aminitrozole was effective in enterohepatitis (blackhead disease) in turkeys, which condition is caused by a flagellated protozoon, Histomonas meleagridis. As a result of it:

* Received for publication April 4, 1957. use in medicated feeds, a constant threat to turkeyraisers has now been removed (Brackett, 1956). The drug is manufactured for this purpose under the name "Enheptin".

Following this discovery, it was inevitable that the drug should be tried in other protozoal diseases. Cuckler, Kupferberg, and Millman (1955) showed that aminitrozole had a high order of anti-trichomonal activity in vitro. In comprehensive work relating to experimentally-produced intra-peritoneal infections with $T$. foetus in mice, they showed that aminitrozole given orally or intraperitoneally in doses of $50-100 \mathrm{mg} . / \mathrm{kg}$. was "highly or completely effective in eradicating the experimental bodycavity infection". A therapeutic effect was also claimed against experimentally-induced $T$. vaginalis infections in monkeys when the drug was given orally. All of three monkeys were microscopically negative for 7 weeks, although only one was culturally negative during this time. There have since been some clinical reports relating to human infections in the U.S.A.

Plentl, Gray, Neslen, and Dalali (1956) treated 124 females with vaginal trichomoniasis with aminitrozole in a daily dosage of $300-600 \mathrm{mg}$. for 6-10 days and claimed a parasitological cure-rate of 37 per cent. With higher dosages, the subjective side-reactions (nausea, abdominal pains, anorexia, and, occasionally, dark discolouration of the urine) were "disturbing" although no abnormal changes were detected in blood or urine. These could be obviated by reducing the daily dose to $300 \mathrm{mg}$. over a period of 7-10 days. Of 48 patients so treated, the parasitological cure-rate was 35 per cent.

Perl, Guttmacher, and Raggazoni (1956) claimed that aminitrozole administered orally (in daily doses of $300 \mathrm{mg}$. for 10 days) would eliminate culturally detectable trichomonads from approximately onethird of women whose marital partners were not treated: 188 patients were given one to four such 
treatments, and negative cultures were obtained in 92 of 137 patients who were followed, but local therapy with an acid jelly was also given twice daily over the same time. The importance of treating both partners simultaneously was emphasized and a 10-day course of aminitrozole was claimed to produce negative seminal cultures in sixteen of 28 men so treated.

During recent months, two preparations of aminitrozole have appeared on the British market, namely Tritheon (Ortho Pharmaceutical Ltd.) and Trichorad (Ward, Blenkinsop, and Co. Ltd.). Tritheon is advertised as "the first oral therapy for trichomoniasis in the male and female", with the remark that "clinical investigation has conclusively demonstrated" that more than 70 per cent. of female patients will have a culture-proved cure if the husbands are simultaneously treated. The reference given is "Perl, G. Personal communication". Trichorad is also stated to be "effective in both male and female" and "because of its systematic (sic) action it reaches resistant trichomonads throughout the genito-urinary tract".

\section{Present Investigations}

If these claims could be even partially substantiated, the introduction of this drug would represent a great advance in the treatment of this condition. Sixteen patients with vaginal trichomoniasis have therefore been treated with aminitrozole (Tritheon) given orally, with no other medication, to ascertain whether there was any noticeable effect.

\section{Material}

Ten of the patients were single, five were married, and one was a widow. The average age was 28.4 years (extremes 16 and 55). Four had had no previous venereal trouble, four had been treated for syphilis in some form, five had had gonorrhoea, one had been treated on epidemiological grounds, and eight had previously been treated locally for vaginitis, $T$. vaginalis, having been isolated in three of them.

The Wassermann reaction and Kahn test were negative in fourteen, Wassermann negative and Kahn positive in one, and both positive in one. Gonococci were found in the smears of two patients and they were given penicillin. The gonococcal complement-fixation test was negative in fourteen, doubtfully positive in one, and not done in one.

In all cases, trichomonads were identified in wet specimens by dark-field examination before treatment. Cultures were not employed. There was a tendency later in the series, as bad results were consistently obtained, to choose the more chronic or subacute cases, as it was not felt fair to treat patients who were intensely uncomfortable from acute vaginitis with ineffective therapy.

\section{Results}

Aminitrozole (Tritheon) was given orally in $100 \mathrm{mg}$. pink-coated tablets three or four times a day for 6 to 14 days. No local treatment was given and no special effort was made to secure and treat male consorts. The object of the investigation was purely to determine whether these tablets had any action at all in vaginal trichomoniasis. No untoward sideeffects were noted, but the clinical results were uniformly bad (see Table).

\section{TABLE}

RESULTS OF TREATMENT OF SIXTEEN CASES OF VAGINAL TRICHOMONIASIS WITH AMINITROZOLE (TRITHEON)

\begin{tabular}{|c|c|c|c|c|c|}
\hline $\begin{array}{l}\text { Total } \\
\text { Dose } \\
\text { (g.) }\end{array}$ & $\begin{array}{l}\text { Daily } \\
\text { Dose } \\
\text { (mg.) }\end{array}$ & $\begin{array}{c}\text { Duration } \\
\text { of } \\
\begin{array}{c}\text { Treatment } \\
\text { (days) }\end{array}\end{array}$ & $\begin{array}{l}\text { Patients } \\
\text { Treated }\end{array}$ & $\begin{array}{l}\text { Patients } \\
\text { Followed }\end{array}$ & $\begin{array}{l}\text { Trichomonads } \\
\text { Present at End } \\
\text { of Therapy }\end{array}$ \\
\hline $\begin{array}{l}4 \cdot 9 \\
4 \cdot 2 \\
3 \cdot 0 \\
2 \cdot 8 \\
2 \cdot 4 \\
2 \cdot 1 \\
1 \cdot 8\end{array}$ & \begin{tabular}{|c|}
$300-400$ \\
300 \\
300 \\
400 \\
400 \\
300 \\
300 \\
\end{tabular} & $\begin{array}{r}14 \\
14 \\
10 \\
7 \\
6 \\
7 \\
6\end{array}$ & $\begin{array}{l}1 \\
1 \\
1 \\
2 \\
2 \\
2 \\
5 \\
4\end{array}$ & $\begin{array}{l}1 \\
1 \\
1 \\
2 \\
1 \\
3 \\
4\end{array}$ & $\begin{array}{l}1 * \\
1 \\
1 t \\
2 \\
1 \ddagger \\
3 \\
4\end{array}$ \\
\hline Totals & .. & $\ldots$ & 16 & 13 & 13 \\
\hline
\end{tabular}

- Trichomonads present at 7 days, absent at 14 days, present at 21 days.

$\dagger$ Also given oxytetracycline for cystitis.

$¥$ Adjudged a failure after only 2 days, and treated locally because the vaginitis had become very acute.

Thus, of sixteen women treated, thirteen were followed and trichomonads were recovered after treatment from them all. In addition, some 49 cases of non-gonococcal urethritis in males were also treated with aminitrozole without noticeable effect.

\section{Discussion}

It is evident that the reported American results have not been confirmed in this series of British patients. Possible reasons for this include:

(1) undetected capriciousness of cultural findings in reported American series;

(2) the use of additional local treatment which was not reported, or which was used by the patients unknown to the American physicians;

(3) differences in sensitivity between the American and British trichomonads;

(4) differences in the host;

(5) differences in the aminitrozole preparations.

It is unlikely that $T$. vaginalis in the U.S.A. differs materially from that found in Great Britain. In a number of instances it must be the same strain. 
Neither do undetectable differences in the host offer a likely explanation. It is conceivable that there may be differences in the preparation-for example, if the coating of the British tablets were too insoluble, insufficient absorption might take place.

\section{Summary}

(1) Aminitrozole has for some years been successfully used in medicated feeds in the prevention of enterohepatitis (blackhead disease) in turkeys. This disease is caused by a flagellated protozoon.

(2) The experimental use in animals and preliminary reports from America of its use in human trichomoniasis have been reviewed. A considerable degree of success has been claimed.
(3) Sixteen patients with vaginal trichomoniasis have been treated with Tritheon tablets given orally in a daily dosage of $300-400 \mathrm{mg}$. over a period of 6 to 14 days, total dosage of 1.8 to $4.9 \mathrm{~g}$. In all the thirteen patients followed, $T$. vaginalis was recovered after therapy.

(4) The possible reasons for the discrepancy between these and the American results are discussed.

\section{REFERENCES}

Brackett, S. (1956). In "Symposium on Medicated Feeds", ed. Welch, H., and Marti-lbañez, F., p. 101. Medical Encyclopedia, New York.

Cuckler, A. C., Kupferberg, A. B., and Millman N. (1955). Antibiot. and Chemother., $5,540$.

Perl, G., Guttmacher, A. F., and Raggazoni, H. (1956). Obstet. Gynec., 7, 128.

Plentl, A. A., Gray, M. J., Neslen, E. D., and Dalali, S. J. (1956). Amer. J. Obstê. Gynec., 71.116.

Waletzky, E. (1950). Turkey World, May. 